\title{
Seno prepúbico congénito. A propósito de un caso
}

\author{
Suárez Filippin P, Ortiz Rodríguez F, López Tosoni MI, Álvarez Portela P, \\ Brzezinski Niedzwiecki M, Sanguinetti Baun H.
}

División Urología. Hospital de Clínicas “José de San Martín”. Universidad de Buenos Aires. Argentina.

Actas Urol Esp. 2008;32(3):351-356

\section{RESUMEN}

SENO PREPÚBICO CONGÉNITO. A PROPÓSITO DE UN CASO DE UN CASO

El seno prepúbico congénito es un tipo de duplicación uretral poco frecuente, de etiología desconocida. Se han propuesto distintas teorías embriológicas, como así también diversas clasificaciones. La mayoría de los casos se diagnostican en la infancia, la cistouretrografía retrógrada y miccional es el estudio fundamental, tanto para confirmar el diagnóstico como para establecer el tipo de anomalía y la mejor opción terapéutica.

Presentamos un caso de seno prepúbico congénito en un varón de 39 años de edad, diagnosticado por secreción purulenta a nivel de un meato accesorio en base del pene.

Palabras claves: Seno prepúbico. Uretra. Congénito. Duplicación.

\section{ABSTRACT \\ CONGENITAL PREPUBIC SINUS: CASE REPORT}

The prepubic congenital sinus is a rare type of urethral duplication of unknown origin. Different embryological theories and classifications has been proposed. Most cases are diagnosed during childhood. The Retrograde Urethrocystography is very important as it determines the diagnosis and helps choosing the best treatment option.

We present a case of a prepubic congenital sinus in a 39 years old male who presented with purulent discharge from an accessory meatus in the base of the penis.

Keywords: Prepubic sinus. Urethra. Congenital. Duplication.

$\mathrm{E}$ 1 seno prepúbico es una entidad congénita poco frecuente, en la literatura los casos descriptos corresponden a la población pediátrica.

El caso clínico que se presenta tiene características particulares, lo que ha motivado a los autores la comunicación del mismo.

A continuación se expondrá el caso clínico, detallando la metodología diagnóstica, terapéutica utilizada y revisión bibliográfica.

\section{CASO CLÍNICO}

Paciente de 39 años de edad, con antecedentes de un episodio de infección urinaria. Consulta por secreción purulenta por un orificio en base de pene (cara dorsal). Al examen físico: se observa orificio en raíz de pene cara dorsal de aproximadamente $3 \mathrm{~mm}$ de diámetro, con secreción purulenta espontánea y maniobras de expresión (Fig. 1) y otro orificio puntiforme a nivel de la cara dorsal del glande, con un meato uretral normoinserto y de características normales (Fig. 2).

Uretrografia retrograda y miccional: En la placa simple se observa diástasis de la sínfisis pubiana (Fig. 3).Las imágenes con contraste obtenidas a través del meato normo inserto muestran una uretra de características normales (Fig. 4). Las imágenes obtenidas con contraste por el meato epispádico muestran un recorrido sinuoso retro-púbico que alcanza la cara anterior de la vejiga sin desembocar en la misma (Fig. 5).

Uretrocistoscopía: realizada por meato uretral normo inserto. Uretra normal. Como hallazgo se 


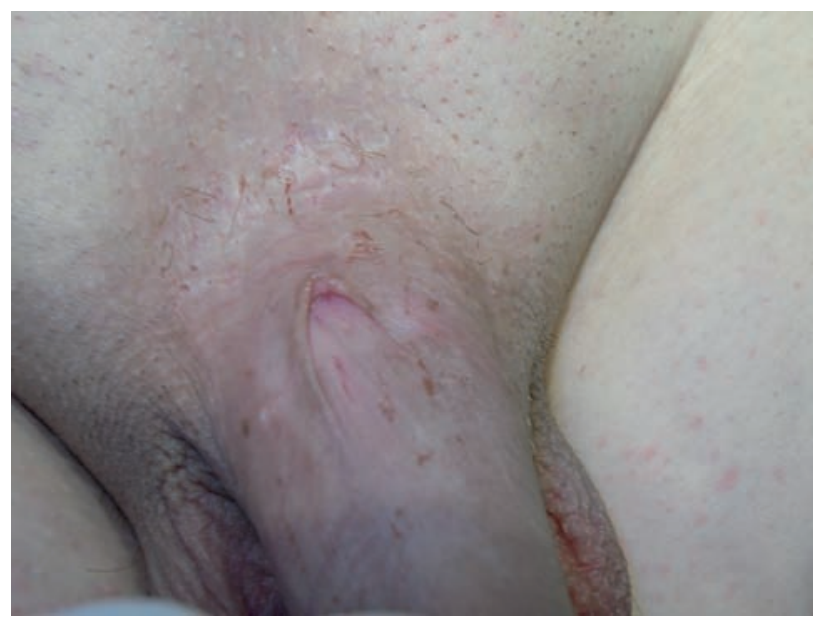

FIGURA 1

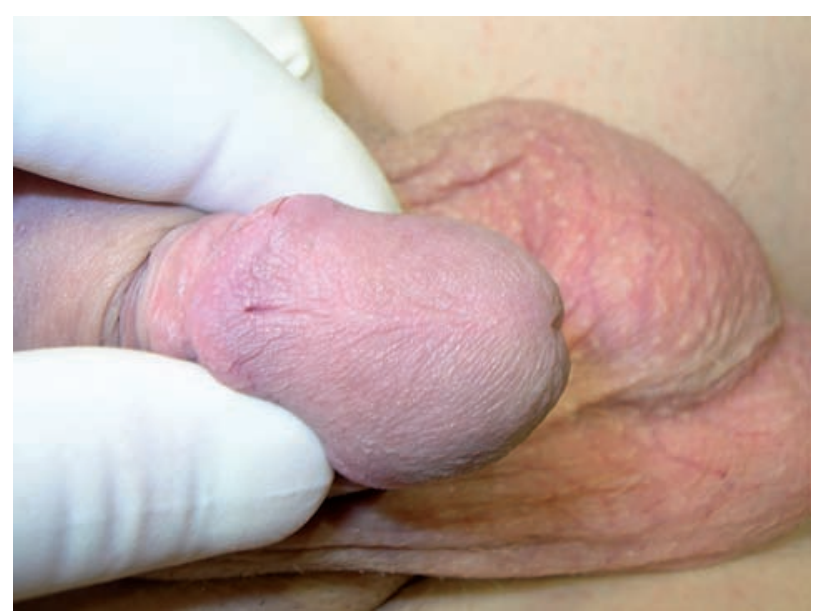

FIGURA 2

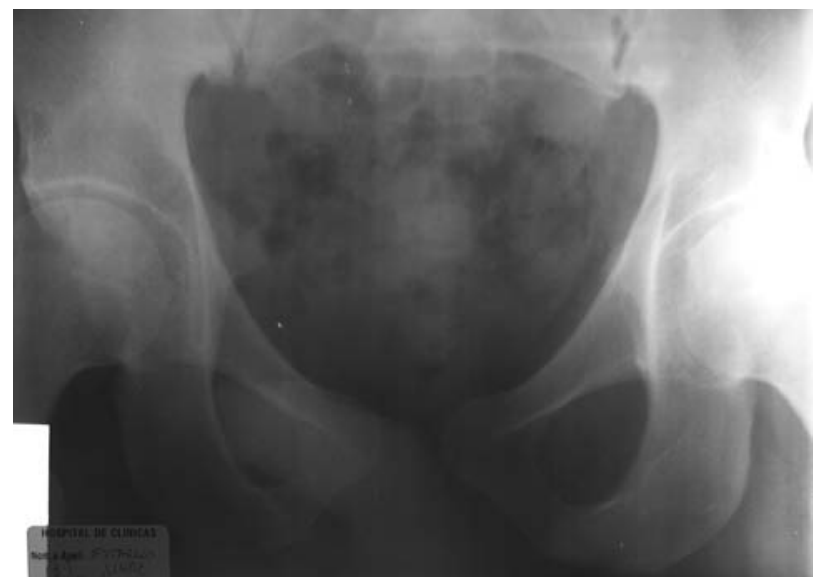

FIGURA 3

observaron lesiones sésiles en hora 12 techo y perimeatal derecha y en cúpula vesical formación una tuberosa que impresiona continuarse con trayecto vermiforme hacia distal (Fig. 6).
Urograma excretor: no se evidencian alteraciones. Ecografia trans-rectal: próstata de 20 g, vesículas seminales bilaterales de aspecto normal.

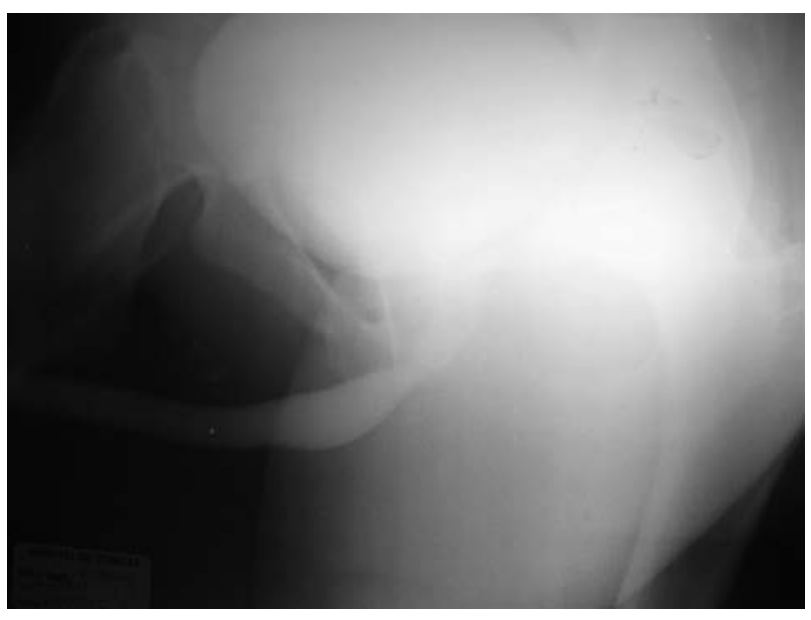

FIGURA 4

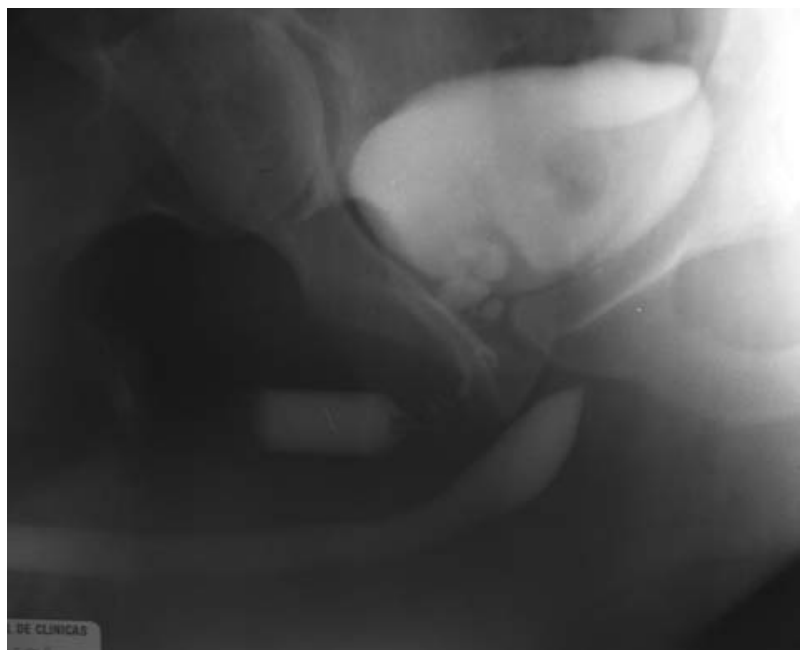

FIGURA 5

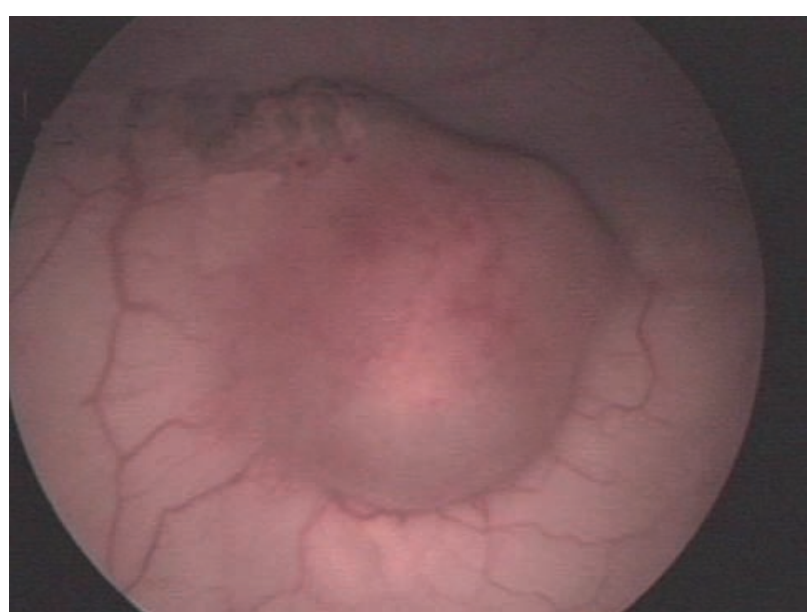

FIGURA 6 
Se decide realizar resección transuretral de vejiga, cuyo estudio anatomopatológico informa carcinoma urotelial de bajo grado TA G1.

Uro-resonancia magnética nuclear: Riñones y sistema ureteropielocalicial sin alteraciones, vejiga con mínima irregularidad parietal posterolateral derecha. Imagen sobre pared anterior que protruye a luz vesical en espacio de Retzius (flecha negra) y se extiende a raíz dorsal del pene (flecha blanca). (Fig. 7).

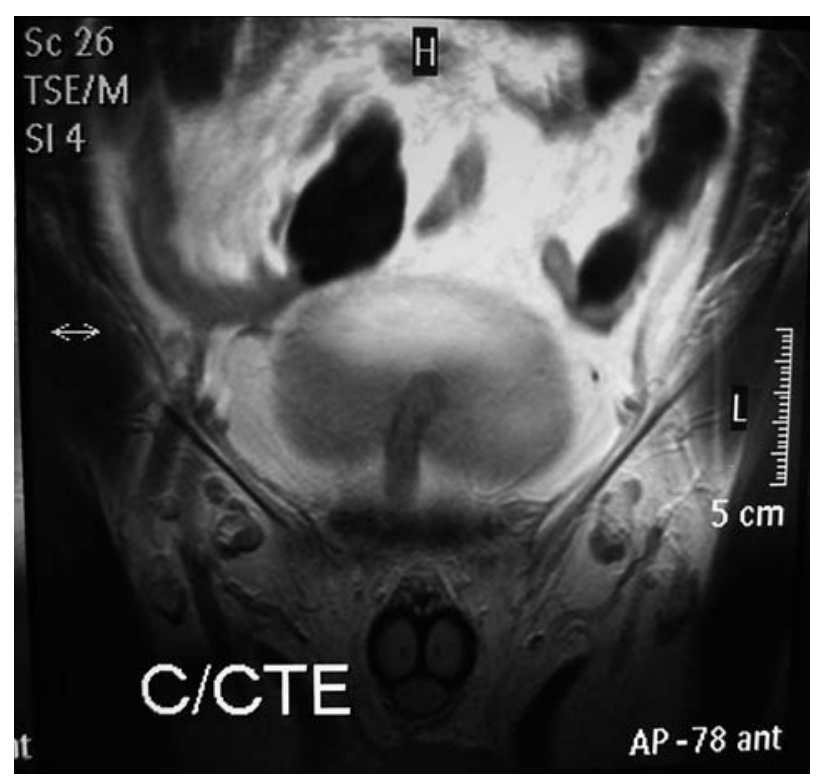

FIGURA 7

Resonancia magnética nuclear de vejiga y pene con Gadolinio: Imagen ya descripta que impresiona canalicular, se dirige a raíz de pene, en línea media dorsal hasta piel compatible con uretra doble. (Figs. 8 y 9).

\section{Cirugia}

Se realiza incisión en raíz de pene para-basal, rodeando meato de uretra doble epispádica, y se diseca alrededor de la misma hacia cara anterior del pubis.

Incisión mediana infra-umbilical, se accede al espacio pre-vesical identificando la llegada del trayecto de la uretra accesoria a la cara anterior de la vejiga, y hacia distal hasta la disección previa, pasando dicho trayecto por detrás del pubis. Se reseca medallón de vejiga en bloque con el trayecto, constatando su contigüidad con el peritoneo y probablemente con el uraco. Se realiza cistorrafia previa colocación de sonda Foley triple vía, luego cierre por planos. (Figs. 10, 11, 12 y 13).

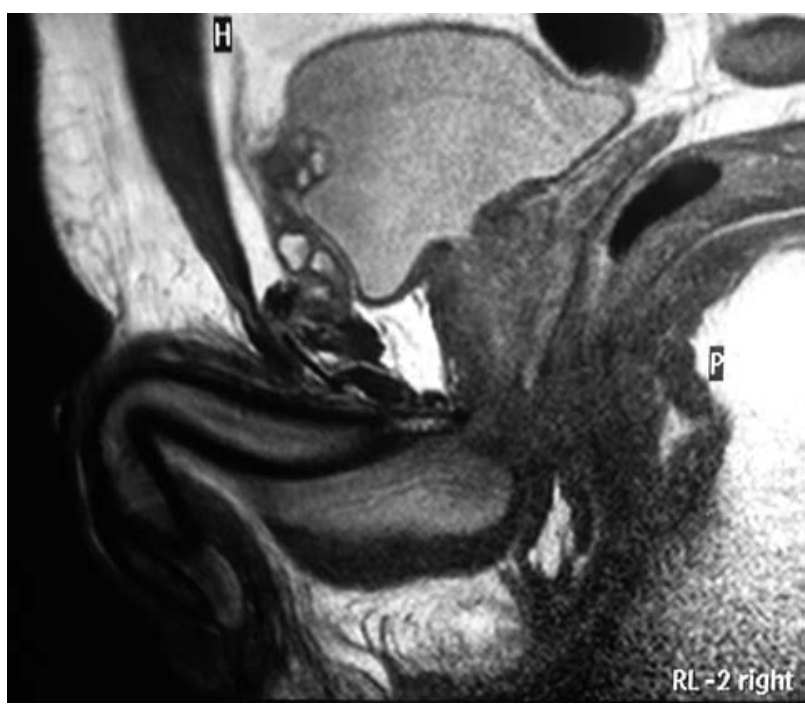

\section{FIGURA 8}

Anatomía Patológica: Los cortes histológicos corresponden a uretra epispádica y manguito vesical, que muestran paredes revestidas por epitelio transicional con infiltrado inflamatorio mononuclear a nivel del corion. (Fig. 14 y 15)

\section{DISCUSIÓN}

Las duplicaciones uretrales son anomalías poco frecuentes y complejas, en la literatura anglosajona se han descrito menos de 20 casos de seno prepúbico congénito desde la descripción de Campell en $1987^{1}$. Se cree que las distintas variaciones que se presentan se deben a diversas anormalidades embriológicas. Estas malformaciones afectan con mayor frecuencia al sexo masculino, y generalmente se asocian con otras malformaciones genitourinarias y extraurinarias ${ }^{2-4}$.

Desde el punto de vista embriológico, la duplicidad uretral parece ser la consecuencia de un trastorno en la implantación del espolón urorrectal de Tourneaux y de los pliegues laterales de Rathke, que en condiciones normales dividen la membrana cloacal en un segmento urogenital y otro rectal. Estas formaciones aparecen hacia la tercera semana de gestación y se completa hacia el cuarto mes ${ }^{4,5}$.

Aquellos casos con uretra dorsal epispádica y diástasis de la sínfisis púbica, parecen relacionarse con trastornos de la fusión mesodérmica en la línea media, con excepción de los casos conocidos como seno prepúbico, en los cuales la presencia de epitelio de transición rodeado de bandas de músculo liso, 


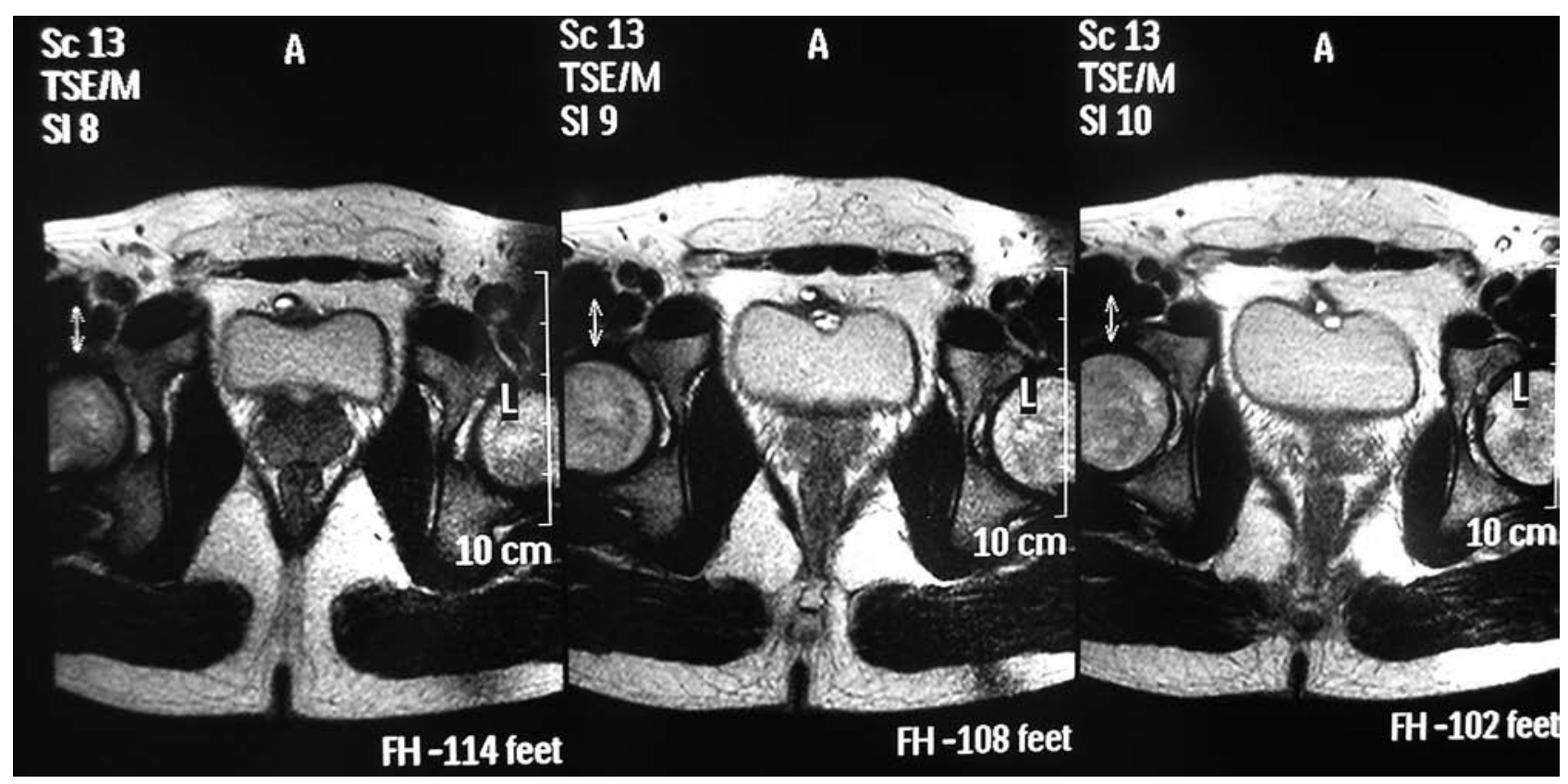

FIGURA 9

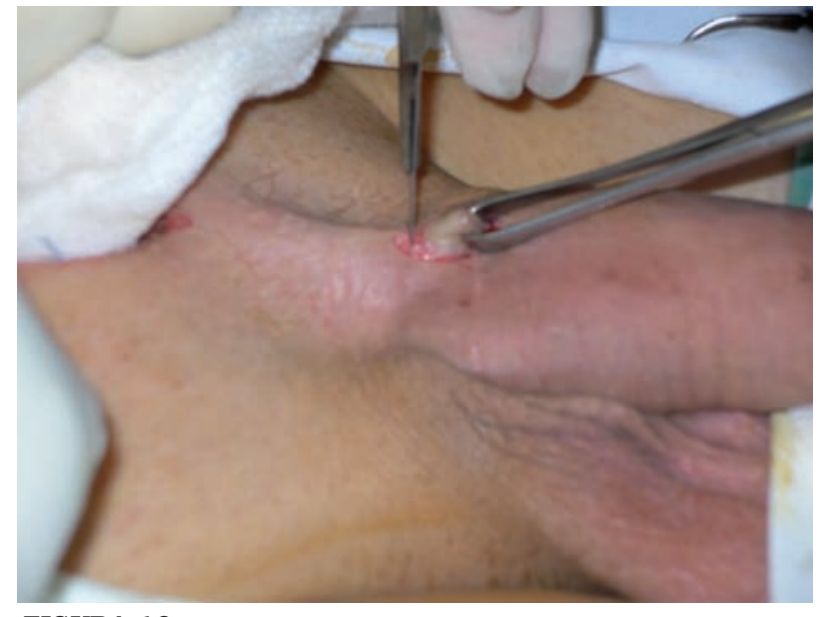

FIGURA 10

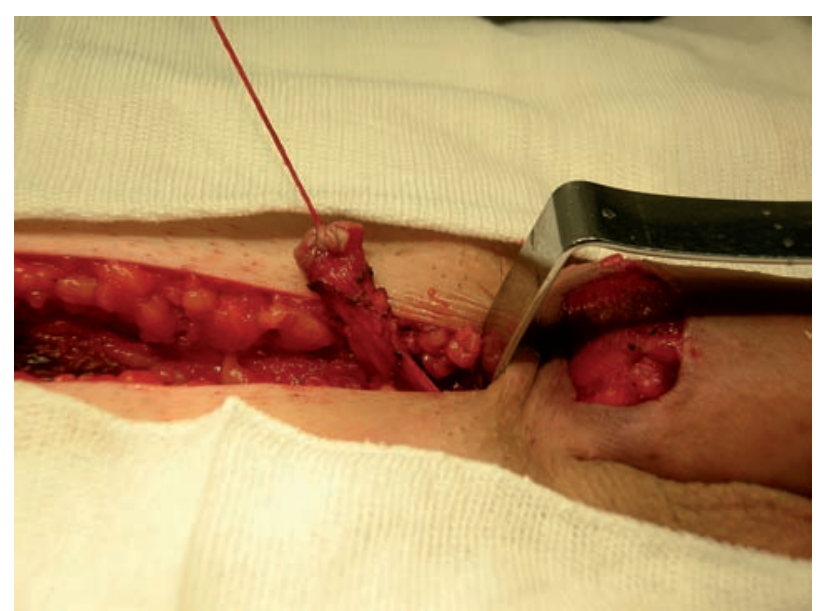

FIGURA 11

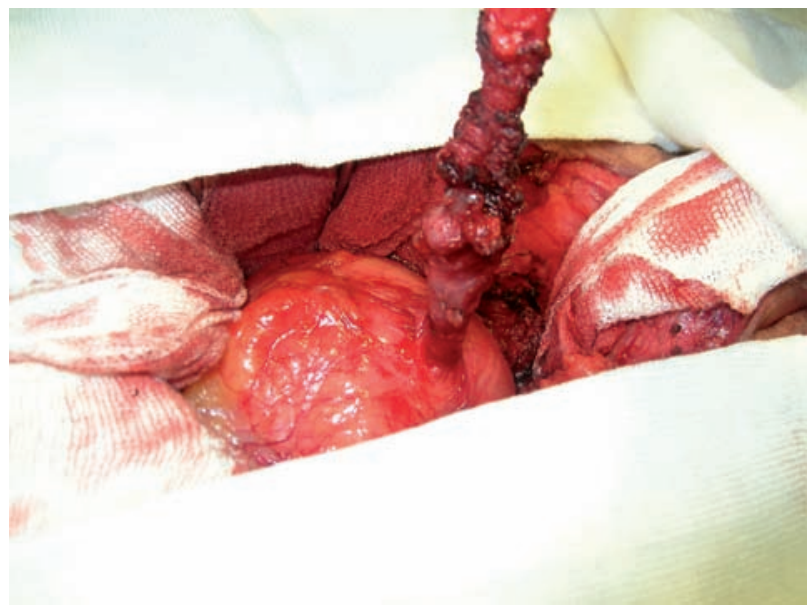

FIGURA 12

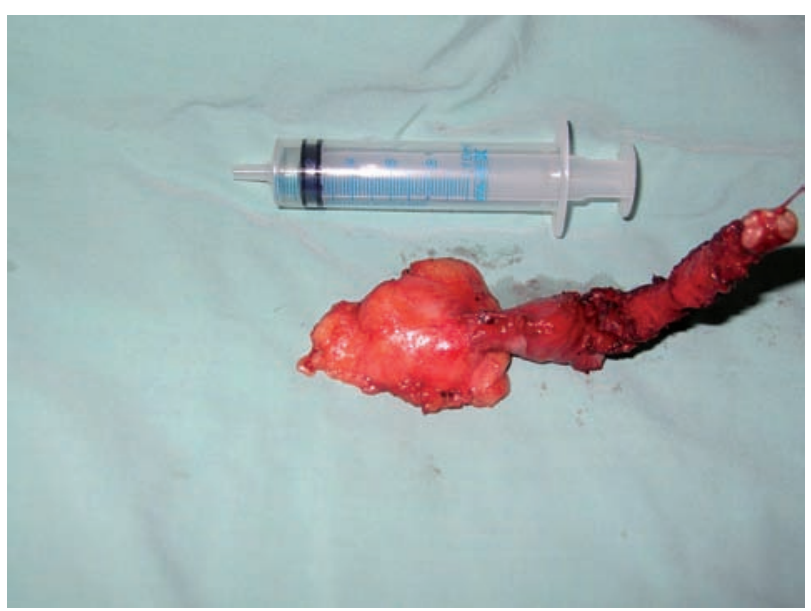

FIGURA 13 


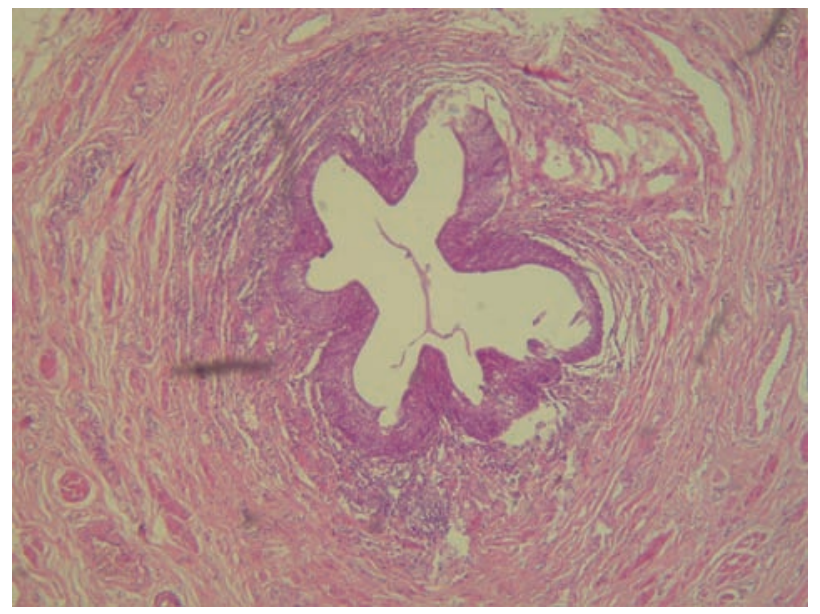

\section{FIGURA 14}

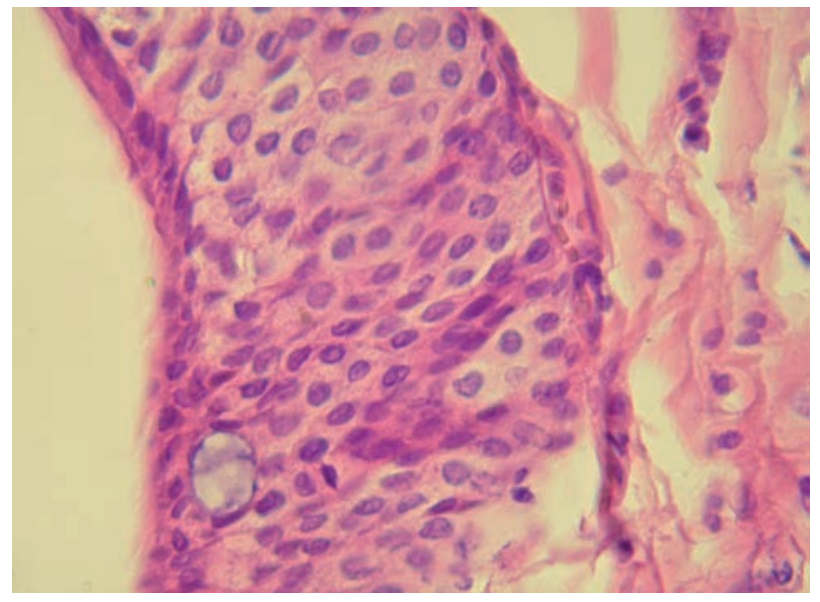

FIGURA 15

refuerzan la teoría de que se trata de una variedad de duplicación uretral dorsal, como se ha demostrado en diferentes publicaciones ${ }^{1,2}$.

La mayoría de los pacientes con seno prepúbico congénito se diagnostican en la edad pediátrica, por la observación de un meato localizado en la base del pene, sobre su cara dorsal. Como síntoma principal hay que mencionar la descarga purulenta por el orificio del mismo, siendo infrecuente que se acompañe de otras manifestaciones.

De las diferentes clasificaciones que pretenden agrupar a las duplicaciones uretrales, la más usada es la de Effmann ${ }^{3-5}$ (Tabla 1), pero ésta no incluye al seno prepúbico, el cual se encuentra contemplado en la clasificación de Stephens ${ }^{1,6,7}$ (1983), y que reconoce tres grupos:

1) Un canal completo o incompleto que corre cerca y paralelo a la uretra normal desde el glande a la vejiga, y que puede unirse a la uretra o terminar en forma ciega.
Tabla 1. Clasificación de Effrnann de la duplicidad uretral $^{14}$

Tipo I: Duplicidad uretral incompleta o uretra accesoria ciega.

IA: De localización distal. La uretra accesoria se abre en la cara dorsal o ventral del pene sin comunicar ni con la uretra principal ni con la vejiga.

IB: Localizada proximalmente y difícil de diferenciar de un divertículo uretral o de una glándula de Cowper. La uretra accesoria parte de la uretra principal y termina de forma ciega en el tejido periuretral.

Tipo II: IIA: Con dos meatos.

IIA1: Dos uretras no comunicadas entre si que se originan de forma independiente en la vejiga.

IIA2: La uretra accesoria se origina en la uretra principal y termina en un meato independiente. De este grupo existe una variante en Y con un meato abierto al periné.

IIB: Con un meato. Poco frecuente. La uretra accesoria se origina independientemente en vejiga o en la uretra posterior y se fusiona con la principal para terminar en un único meato.

Tipo III: Duplicidad uretral en el contexto de una duplicidad de las estructuras caudales.

2) Un canal epispádico que comunica con la vejiga o la uretra normal.

3) Un seno que simula una uretra pero corre desde la base del pene por delante de la uretra normal y de la vejiga, pasa por debajo de la sínfisis pubiana hasta el ombligo.

La exploración física del paciente, con el hallazgo de dos meatos uretrales, es a menudo suficiente para establecer el diagnóstico de sospecha.

La cistouretrografía retrograda y miccional es el procedimiento que ofrece una mayor utilidad para confirmar el diagnóstico, permitiendo a la vez determinar el tipo de duplicidad.

La uretrocistoscopía a pesar de ser una prueba invasiva, es necesaria para determinar ciertas características de la uretra, como la ubicación exacta del verum montanum y del esfínter estriado, que permiten la identificación de la uretra funcional ${ }^{2,4}$.

Es conveniente siempre realizar un urograma excretor, ya que como se dijo, la duplicidad uretral puede estar asociada con otras anomalías congénitas del tracto urinario superior ${ }^{2,4,5,8}$. 
El tratamiento de la duplicidad uretral es muy variable, ya que depende del tipo de duplicidad, de la repercusión funcional y de la coexistencia de otras malformaciones ${ }^{2,3}$.

En líneas generales el tratamiento quirúrgico debe ser considerado en caso de alteración estética significativa, chorro miccional doble, dificultad para el vaciamiento vesical, infecciones a repetición e incontinencia urinaria ${ }^{2-4}$.

Salle et al. propusieron un esquema terapéutico orientador $^{4}$ (Tabla 2).

Tabla 2. Esquema terapéutico propuesto por Salle et al. ${ }^{15}$

\begin{tabular}{|c|c|c|}
\hline Tipo & & Tratamiento \\
\hline IA & \multirow{2}{*}{\multicolumn{2}{|c|}{$\begin{array}{l}\text { Meatoplastia o exéresis de la uretra accesoria } \\
\text { Abstención terapéutica }\end{array}$}} \\
\hline IB & & \\
\hline IIA1 & \multicolumn{2}{|c|}{$\begin{array}{l}\text { Uretro-uretrostomía exéresis de uretra } \\
\text { accesoria con o sin uretroplastia }\end{array}$} \\
\hline IIA2 & \multicolumn{2}{|c|}{ Uretroplastia } \\
\hline IIB & \multirow{2}{*}{\multicolumn{2}{|c|}{ Abstención terapéutica }} \\
\hline \multirow{2}{*}{\multicolumn{3}{|c|}{ Coranal: }} \\
\hline & & \\
\hline \multicolumn{2}{|c|}{ Sin difalia } & $\begin{array}{l}\text { Exéresis del septo vesical o la hemi- } \\
\text { vejiga + reimplante ureteral en vejiga } \\
\text { contralateral. Para la uretra lo mismo } \\
\text { que para el tipo IIAl. }\end{array}$ \\
\hline & difalia & $\begin{array}{l}\text { Penoplastia + glandeplastia. Para la } \\
\text { vejiga el esquema anterior }\end{array}$ \\
\hline \multicolumn{2}{|c|}{ Sagital } & $\begin{array}{l}\text { Exéresis de la vejiga no funcional. } \\
\text { Para la uretra lo mismo que IIAl. }\end{array}$ \\
\hline
\end{tabular}

\section{REFERENCIAS}

1. Huang CC, Wu WH, Chai CY, Wu TC, Chuang JH. Congenital Prepubic sinus: A variant of dorsal urethral duplication suggested by histochemical analysis. J Urol. 2001 Nov;166(5):18761879.

2. González E. (h.): Válvulas uretrales posteriores y otras anomalías uretrales: Urología de Campbell, $8^{\text {a }}$ edición: Cap. 63: 24262427.

3. Hayat Erdil, Ayfer Mavi: Urethral Duplication. Acta Med Okayama 2003:57(2):91-93.

4. Muñoz Vélez D, Riera Marí V, Ozonas Moragues M.: Duplicidad uretral incompleta en un varón. Actas Urol Esp. 2005;29(1):9395.

5. Rodríguez Alonso A, Cespón Outeda E, González Blanco A, Bonelli Martín C, Lorenzo Franco J, Cuerpo Pérez MA et al. Duplicidad de uretra masculina. Actas Urol Esp. 2002;26(1):6973.

6. Campbell J, Beasley S, Mc Mullin N. Congenital Prepubic Sinus: Possible variant of dorsal urethral duplication. The Journal of Urology, March 1987. Vol. 137: 505-506.

7. Stephens F. Abnormal Embryology-Cloacal Dysgenesis: Preger Scientific 1983, Part 1: 22.

8. Rodríguez Tolrá J, Cuadrado Campaña JM, Buisan O, Francés I Comalat A, Franco Miranda E, Serrallach Milá N.: Duplicidad uretral incompleta. Actas Urol Esp. 2005;29(7):697-699.

Correspondencia autor: Dr. P. Suárez Filippin Hospital de Clínicas General San Martín (UBA) Av. Córdoba 2351. Capital Federal. Argentina. Tel.: 54 (011) 59508815

E-mail autor: urologiacatedra@yahoo.com.ar Información artículo: Nota clínica

Trabajo recibido: julio 2006

Trabajo aceptado: octubre 2006 